\title{
PI5- I 2. Community advisory boards' successes and challenges in AIDS vaccine clinical trials: a Southern Africa experience
}

\section{T Mokhele}

\author{
Address: Country and Regional Programme, IAVI - Southern Africa Regional Office, North Riding, South Africa \\ from AIDS Vaccine 2009 \\ Paris, France. 19-22 October 2009 \\ Published: 22 October 2009 \\ Retrovirology 2009, 6(Suppl 3):P2I3 doi:10.1 I86/I742-4690-6-S3-P2।3
}

This abstract is available from: http://www.retrovirology.com/content/6/S3/P2/3

(c) 2009 Mokhele; licensee BioMed Central Ltd.

\section{Background}

This paper presents the successes and challenges experienced by Community Advisory Boards (CABs) across AIDS vaccine Clinical Research Centers (CRCs) collaborating with the International AIDS Vaccine Initiative (IAVI) in Southern Africa. CABs serve as a link between researchers and the community where research is taking place.

\section{Methods}

Since 2006, IAVI has conducted 15 needs assessment sessions with 13 different CABs from South Africa and Zambia. Based on the findings, a CAB skills building program was developed, three regional $\mathrm{CAB}$ exchange meetings were held and 11 interactive skills building sessions were conducted. These sessions provided a platform for CABs to discuss and address $\mathrm{CAB}$ capacity building needs, challenges and successes, while considering their diversity and the need to adapt best practices to local contexts. These meetings also sought to address major challenges identified by CABs, such as reaching out to different communities, inconsistent capacity building efforts, unclear roles and responsibilities, language barriers, lack of proper understanding of scientific concepts, inadequate co-ordination and planning of $\mathrm{CAB}$ activities, inadequate induction of new $\mathrm{CAB}$ members and poor retention of $\mathrm{CAB}$ members. Based on the successes and effective actions reported by participants, best practices were identified and shared.

\section{Results}

The skills building and exchange efforts were acknowledged as contributing to build mutually beneficial relationships between CABs and research teams, to establish community trust and ultimately to a smooth implementation of research programs. By providing opportunities for exchange and capacity building across sites at the regional level, the process also has contributed to strengthen national/regional benchmarks for community engagement and CABs.

\section{Conclusion}

Regular technical support of CRCs and CABs contributes positively towards improved functioning of CABs and further contributes to ensuring meaningful community participation in clinical trials. 